\title{
The Effect of Leisure Involvement and Leisure Satisfaction on the Well-Being of Pickleball Players
}

\author{
Qing Chen ${ }^{1}$, Cheng Yun Chou ${ }^{2}$, Chao-Chien Chen ${ }^{2}$, Jan-Wei Lin ${ }^{3}$ and Chin-Hsien Hsu ${ }^{4, *}$ (i) \\ 1 College of Physical Education, Sichuan University, Chengdu 610065, China; Chen_qing@scu.edu.cn \\ 2 Department of Leisure and Recreation Management, Asia University, Taichung 41354, Taiwan; \\ smallchou1013@gmail.com (C.Y.C.); peter72@asia.edu.tw (C.-C.C.) \\ 3 Center for General Education Sports Administrative Organization, National Chi Nan University, \\ Nantou County 54561, Taiwan; cwlin@ncnu.edu.tw \\ 4 Department of Leisure Industry Management, National Chin-Yi University of Technology, \\ Taichung 41170, Taiwan \\ * Correspondence: hsu6292000@yahoo.com.tw
}

Citation: Chen, Q.; Chou, C.Y.; Chen, C.-C.; Lin, J.-W.; Hsu, C.-H. The Effect of Leisure Involvement and Leisure Satisfaction on the Well-Being of Pickleball Players. Sustainability 2022, 14, 152. https://doi.org/ $10.3390 /$ su14010152

Academic Editors: Sidonio Serpa and Jürgen Beckmann

Received: 3 November 2021

Accepted: 14 December 2021

Published: 24 December 2021

Publisher's Note: MDPI stays neutral with regard to jurisdictional claims in published maps and institutional affiliations.

Copyright: (C) 2021 by the authors. Licensee MDPI, Basel, Switzerland. This article is an open access article distributed under the terms and conditions of the Creative Commons Attribution (CC BY) license (https:// creativecommons.org/licenses/by/ $4.0 /)$.

\begin{abstract}
The purpose of this study is to investigate the effect of leisure involvement and leisure satisfaction on the well-being of pickleball players. This study enrolled 260 participants from the 2019 International Pickleball Tournament by purposive sampling. A total of 250 questionnaires were returned, for a return rate of $96 \% ; 215$ questionnaires were valid, for an effective recovery rate of $86 \%$. The data were archived using SPSS 24.0, and the correlation between variables was analyzed using AMOS 24.0. By analyzing the empirical data in this paper, the following main findings were obtained: (1) leisure involvement has a significant effect on leisure satisfaction; (2) leisure involvement does not have a significant effect on well-being; (3) leisure satisfaction has a significant effect on well-being; and (4) leisure satisfaction has a mediating effect on the relationship between leisure involvement and well-being.
\end{abstract}

Keywords: pickleball; leisure involvement; leisure satisfaction; well-being

\section{Introduction}

With the successful conclusion of Tokyo 2020, the world once again witnessed the charm of sports, and its ability to stimulate people's imagination. Notably, the addition of surfing, skateboarding, sport climbing, and other youth-friendly sports to this year's Olympic Games created a buzz around the Olympics, and the emerging sports and street sports of the past have gradually formed a sub-culture, and spread globally. In recent years, emerging sports have been developing into communities around the world, which are characterized by their non-mainstream nature and low barriers to entry, as exemplified by various sports, such as dodgebee, VX, Mölkky, pickleball, and kabaddi. Among the many emerging sports, pickleball is considered to be one of the fastest-growing sports in the United States today, and it is preferred by all ages, especially by seniors [1]. Unlike other competitive sports, pickleball is easy to pick up and requires simple equipment. Wray, Ward, Nelson, Sulzer, Dakin, Thompson, Vierimaa, Das Gupta, and Bolton [2] argued that pickleball is very accessible due to its economical and portable equipment, and can be played on a hard and flat surface of any size. Chang [3] further pointed out that pickleball, which originated in the United States, combines the rules of tennis and the field design of badminton, and is played with an enlarged table tennis racket. Pickleball does not stress speed, and has few restrictions on the field. Participants take a "shallow squat" posture to attack and defend, which helps children train joint flexibility, whereas adults or elders can prevent knee degeneration, and enhance their cardiopulmonary function; thus, it is a sport that can be widely practiced by all age groups.

Leisure involvement refers to the players' intrinsic motivation and enjoyment, which leads to their interest and concern for their preferred leisure activities and continuous 
participation [4]. In other words, pickleball is an emerging sport that has fewer participants than other popular sports; however, there is still a group of pickleball enthusiasts who are involved in the sport, and trying to energize the pickleball community. Thus, this paper focused on understanding the psychological state of players who are interested in pickleball, as well as their involvement in the sport. Leisure satisfaction refers to the positive perceptions or feelings that individuals get from participating in leisure activities, meaning the degree of satisfaction that individuals feel in their overall leisure experience and context, and such satisfaction stems from the satisfaction of individuals' perceived or unperceived needs [5]. Though pickleball is characterized by ease of play and low field restrictions, it is worth exploring further whether players gain satisfaction from the physical, psychological, and social benefits of the sport. Well-being is a multifaceted concept that consists of both emotional and cognitive components [6]. The process of playing pickleball generates many subjective personal feelings that affect the players' emotions or perceptions of life, thus, giving rise to the issue of well-being. Therefore, one of the focuses of this paper is to investigate the perceived well-being of pickleball players.

The literature review indicated that most studies on pickleball focused on the participation behavior of seniors [7-9]. For example, Buzzelli and Draper [10] conducted a survey on a total of 3012 older adults that included items from the Sport Motivation Scale, the Task and Ego Orientation in Sport Questionnaire, and the Quality and Importance of Recreational Services, and found that their primary motivation to participate in pickleball involved mastering difficult training techniques. However, participants cited competitions as the top perceived benefit to their participation. Heo, Ryu, Yang, and Kim [9] studied a total of 153 older adults that had competed in pickleball tournaments, and the results revealed that serious leisure and depression were inversely related, which implies that commitment to serious leisure is associated with lower levels of depression in older adults. Further analysis that correlated the qualities of serious leisure with depression revealed that career progression and career contingencies were associated with depression. Meanwhile, some studies discussed the sports injuries of pickleball [11,12]; for example, the research objective of Mathias and Forrester [13] was to describe pickleball-related injuries treated in U.S. emergency departments (EDs). A total of 300 pickleball-related injuries were identified, resulting in a national estimate of 19,012 injuries, and $74.3 \%$ of these cases were injuries that occurred at sport or recreational facilities. The most common injuries were strains or sprains $(28.7 \%)$, followed by fractures $(27.7 \%)$, and the affected body parts were the lower extremities in $32.0 \%$ of the cases, followed by the upper extremities at $25.4 \%$. There are also few studies that analyzed pickleball teaching; for example, James [14] pointed out that effectively teaching pickleball skills in physical education could lead to a lifelong participation in pickleball, as well as the possible transfer of skills to more complex racquet sports.

According to the abovementioned relevant literature, the more pickleball participants are involved in pickleball, the higher their leisure benefits; for example, an empirical study by Heo, Ryu, Yang, Kim, and Rhee [1] pointed out that playing pickleball as a form of serious leisure may add significant value to older adults' daily lives, and contribute to successful aging; thus, pickleball plays an important role for participants to obtain benefits. In addition, as they invest far more time, equipment, and energy than people who regard pickleball as an ordinary leisure activity, participants of pickleball tournaments are different from general participants; thus, they should pay more attention to their leisure satisfaction. Moreover, the promotional process of an emerging sport helps the public to understand the impact of this sport on self-physiology. Helping the public to understand how psychological and social benefits affect leisure satisfaction will be very conducive to introducing this sport globally. In addition, research papers that take the leisure behavior of pickleball players as the subject are relatively scarce. Therefore, this study aims to explore the effect of leisure involvement and leisure satisfaction on the well-being of pickleball participants. 


\section{Literature Review and Research Hypotheses}

\subsection{Literature Review}

Pickleball, which was invented in 1965 , is a paddleball sport that combines the elements of tennis, badminton, and billiards [15]. With the promotion of USAPA, the game of pickleball is gradually growing in popularity worldwide. According to $\mathrm{Hsu}$, $\mathrm{Lu}$, and Wang [16], pickleball combines the rules of tennis, billiards, and badminton, and is easier to pick up than other sports, even for people with no previous experience, which makes it a sport that can be enjoyed at any level of intensity, and promotes physical fitness and social interaction. In addition to the ease of acquiring pickleball skills, the promotion of pickleball-related organizations around the world also plays a major role. According to the data of USAPA 2017, the United States, the birthplace of pickleball, not only hosts large and small pickleball tournaments around the country, but, in recent years, has held a lucrative U.S. Open Tournament to draw pickleball players from around the world, with prize money increasing from USD 150,000 for the 2017 champion to USD 300,000 for the 2018 champion. Chinese Taipei's pickleball tournaments are gradually being organized by the relevant associations, such as the 2018 International Pickleball Qualifying Tournament, the 2019 International Pickleball Qualifying Tournament, and the 2020 Asian Pickleball Professional Elite Selection Tournament. These events not only foster more pickleball players, but also boost the spread of pickleball games. As the number of participants increases year by year, it is worthwhile to further investigate the level of involvement, satisfaction, and well-being of the participants in the sport, which could serve as a catalyst for the promotion of pickleball in Chinese Taipei.

Leisure involvement is an imperceptible state of motivation, arousal, or interest that lies between the individual and the recreational activity, destination, or associated equipment, and can be triggered by specific stimuli or conditions [17]. In other words, leisure involvement can be a behavioral sign or a psychological state for the player. In the case of pickleball, in terms of the behavioral sign, a high level of involvement can be a result of long-term practice or a high investment in related equipment. In terms of the psychological state, it can refer to the attractiveness of pickleball to the player. Godbey [18] stated that, according to sociologist Hobson Bryant, there are four stages of leisure involvement. Stage 1: The initial stage: A newcomer starts with a few expectations of the behavior, and some people may stop at this stage, such as a novice fisherman whose goal is to catch a fish by any means necessary. Stage 2: Learning begins to occur. Stage 3: Professional Stage: Individuals begin to develop professional skills for different aspects of the behavior, such as technology, equipment, relevant rules, and other more specialized objects that become important to the participant. Stage 4: The highest professional stage, in which the individual builds their own style in the activity field, and the love of the activity is for one's self. Nevertheless, for pickleball participants, these four stages are not necessarily experienced, especially when pickleball is promoted to the elderly for the purpose of successful aging, rather than to the professional stage. Therefore, Kyle, Graefe, Manning, and Bacon [19] divided leisure involvement into the following five dimensions:

1. Attractiveness: Is this activity the most enjoyable of all leisure activities?

2. Centrality: I realize that almost all aspects of my life are connected to this activity. If I were to change this activity, it would require serious consideration for me.

3. Social Bonding: Whether participation in this leisure activity provides me with the opportunity to make friends, or I enjoy discussing this leisure activity with my friends.

4. Identity Affirmation: When I participate in this leisure activity, I feel like myself; or when I participate in this activity, I don't care how others perceive me.

5. Identity Expression: Participation in this leisure activity allows me to express myself, or I like the way people view me as I perceive myself to be.

According to the above, the classification of Kyle, Graefe, Manning, and Bacon [19] seems to be an appropriate framework to probe into the leisure involvement of the general public.

However, when people get involved in a certain leisure sport, they often encounter different internal and external obstacles, and when such obstacles occur, participants are 
often forced to give up participating, and cannot continue to play. Jackson, Crawford, and Godbey [20] proposed two new concepts on the basis of constructing the leisure hindrance model, namely negotiation and balance. The concept of negotiation refers to the decision of an individual's behavior whether or not to engage in a certain leisure activity, which is not based on the assumption that the individual can participate only after overcoming various obstacles, but rather that the individual will adjust among various obstacles. Obstacles that have been overcome in the negotiation process may arise (overcome, or not perceived) again in the form of a feedback loop. In the process of negotiation, the interaction and intensity between activity obstacles and participation motivation are related, which means that the concept of balance refers to the result of negotiation. There is interplay between obstacles and motivation; it is easy to start playing pickleball, and the venue and equipment are relatively simple compared with other sports. Therefore, regarding the degree of leisure involvement of pickleball players, participants have passed personal internal obstacles, and have a preference for pickleball sports. At the same time, due to the low structural obstacles, the players show a high degree of leisure involvement. In addition, pickleball players may also negotiate against the obstacles encountered in the process; for example, if they cannot find enough players to play doubles, they may turn to singles or pure ball practice. These related factors are worthy of further exploration.

Leisure satisfaction is a subjective relative comparison among related criteria, which may be prior experience, the individual's own expectations, achievements from it, or feelings of satisfaction during leisure activities [21]. In other words, leisure satisfaction is a general term that refers to the gap between an individual's perceived actual performance and his or her goal. In the case of pickleball, the smaller the gap in the player's goal, the higher the satisfaction of the participant, e.g., the smaller the discrepancy between the arrangements of the pickleball tournament and the prior expectation, the higher the satisfaction with the tournament event. As such, leisure satisfaction is a tool used to measure people's perceptions of the desirability of leisure activities when they participate in them. Mannell and Kleiber [22] also suggested that leisure satisfaction is influenced by a combination of motivational needs, such as the emotional, cognitive, and personality traits of leisure participants, and presents different satisfaction outcomes. From this point of view, there are many factors that affect the dimensions of leisure satisfaction to be considered, and this view is also reflected in the measurement of leisure satisfaction. Beard and Ragheb [5] developed the "Leisure Satisfaction Scale", which is based on the view that the needs of individuals are satisfied in leisure activities, and its dimensions include (1) psychological, (2) social, (3) physiological, (4) educational, (5) relaxation, and (6) aesthetic dimensions.

The term "well-being" originally represented an emotion, meaning the individual's subjective cognitive and emotional evaluation of his or her life, with the cognition being an evaluation of the overall life satisfaction, and the emotion being a response to positive emotions, as well as an experience of happiness and pleasure. In other words, well-being depends on a person's perception of what is happening in his or her life, and this perception has an impact on his or her emotions and mental health. Well-being is likely to improve when people have more positive emotions about something, which, in turn, satisfies their psychological state. Keung, and Goswami [6] also held a similar view, and stated that well-being is a multifaceted concept that encompasses emotional and cognitive components: (1) pleasant emotional experience (positive effect); (2) negative emotion, such as sadness and dissatisfaction (negative effect); (3) quality of life self-assessment (including overall life satisfaction and satisfaction with specific items). For pickleball players, the process of participation may be a way to improve their quality of life, either by connecting with friends or through the physiological and psychological benefits of participating in the sport, which leads to a feeling of psychological well-being. Since well-being encompasses both psychological states and perceptions of things, a multidimensional approach is adopted to measure well-being, as suggested by Ryff [23], who assessed individuals' well-being from six different psychological dimensions: self-acceptance, positive relations with others, environmental mastery, autonomy, purpose in life, and personal growth. According to the 
relevant literature compiled by this study, leisure activities have a positive impact on the well-being of participants [24-26]; for example, the research results of Trainor, Delfabbro, Anderson, and Winefield [27] supported previous personality research which suggests that how spare-time is used may be related to well-being only insofar as individuals who are psychologically healthy tend to be involved in structured leisure activities. Pickleball is regarded as one of the fastest growing sports in the United States. It is possible that because pickleball is easy to learn and the equipment is relatively simple, participation will improve leisure satisfaction and further affect well-being. In other words, the characteristics of pickleball and the nature of participation are worthy of further empirical research on leisure satisfaction and well-being.

Regarding the relationship among the variables, relevant studies point out the influence of leisure involvement on leisure satisfaction [28-30]; for example, Chen, Li, and Chen [28] used quantitative research to study 701 adolescents in Central Taiwan to explore the relationship between leisure motivation, leisure involvement, and leisure satisfaction. The research results found that leisure motivation had no significant effect on leisure satisfaction when leisure involvement was included in the model, but leisure motivation had a significant effect on leisure involvement. Tsai and Guo [29] studied the correlation between the leisure involvement and leisure satisfaction of elderly people in Taipei, and found that leisure involvement has a positive and significant relationship with leisure satisfaction. Taking senior citizens as the research subject, this paper discussed the relationship among leisure involvement, leisure satisfaction, and the well-being of senior citizens. Lo [31] conducted a questionnaire survey with senior citizens over 55 as the research subjects, and found that leisure involvement has a significant impact on leisure satisfaction, and the influence of leisure involvement on well-being has also obtained relevant empirical results; for example, Mehmet [32] investigated the leisure involvement and well-being levels of individuals with a fitness center membership. According to the findings, a positively significant relationship was determined between the level of well-being and leisure involvement. Pan, Wu, Morrison, Huang, and Huang [30] conducted a study to investigate the relationship of leisure involvement with the well-being of professional sports fans; and the possible mediating effect of organizational commitment, which is a career-related characteristic, on well-being. Some 406 fans of the Brother Elephants Baseball Team in Taiwan were surveyed, and the results showed that leisure involvement positively and significantly influenced fans' well-being. In addition, the influence of leisure satisfaction on well-being has also been demonstrated [33,34]; for example, the purpose of Kaya's [35] study was to examine the effect of the participation of college students in leisure activities, as well as their level of leisure satisfaction on their well-being, according to various parameters. A total of 1464 college students participated in Kaya's [35] study, and the results showed a significant and positive relationship between all dimensions of leisure satisfaction on well-being. Liu [34] examined the relationships among personality, leisure satisfaction, and subjective well-being in a sample of participants $(N=193)$ in seven arts groups at a key eastern Chinese university, and the results indicated that leisure satisfaction was significantly positively correlated with SWB. In addition, relevant studies have illustrated that leisure satisfaction often plays an intermediary role; for example, Huang [36] took employees of the Taiwan Power Company as the research subjects, and found that leisure satisfaction had a mediating effect on sociability, competence and proficiency, leisure motivation, and well-being. This study also explored whether leisure satisfaction has an intermediary effect on the relationship between leisure involvement and well-being.

Based on the above literature, it can be seen that most studies have adopted quantitative studies, and the relationship between variables in this study is also supported by the above literature. According to the relationships among the variables, the following four research hypotheses are formulated in this paper. 


\subsection{Research Hypotheses}

Hypothesis 1 (H1). For participants in pickleball sports, leisure involvement has a significant effect on leisure satisfaction.

Hypothesis 2 (H2). For participants in pickleball sports, leisure involvement has a significant effect on well-being.

Hypothesis 3 (H3). For participants in pickleball sports, leisure satisfaction has a significant effect on well-being.

Hypothesis 4 (H4). For participants in pickleball sports, leisure satisfaction has a mediating effect on the relationship between leisure involvement and well-being.

As pickleball is still in the promotion stage in Chinese Taipei, it is not as popular as basketball or badminton; thus, there is a lack of related research on the leisure participation behavior of pickleball, and at present, there are no more than 20 relevant discussions. Moreover, most of the current studies in Chinese Taipei focused on the promotion of this sport towards the elderly; for example, $\mathrm{Hsu}, \mathrm{Lu}$, and Wang [16] conducted semi-structured qualitative in-depth 1-on-1 interviews with 24 older pickleball players to understand their experience and acceptance of participating in pickleball sports. The results showed that pickleball is simple and easy to play, with a sense of match achievement, low injury risk, and low cost of consumables. There is also a study on the tournament system of pickleball in Chinese Taipei. Chen, Ma, Yu, and Chiu [37] used the case study method, qualitative research, direct observation, and in-depth interviews to explore the establishment of pickleball tournaments to popularize it among the public, promote it into a national sport, and jointly experience the fun of sports, which is used as the promotion direction to evaluate the feasibility of pickleball tournaments in Chinese Taipei. Regarding the participation behavior of participants in pickleball, it is rarely discussed. As pointed out by $\mathrm{Hsu}, \mathrm{Lu}$, and Wang [16], as pickleball was only recently introduced to Chinese Taipei, there are few coaches, it is difficult to find players, and there are few venues, and these factors may affect the involvement of pickleball players in this activity and leisure satisfaction. In addition, the impact of leisure involvement on well-being and leisure satisfaction on well-being has been empirically demonstrated by relevant studies. Therefore, one of the key points of this paper is to understand the impact of pickleball players on well-being after investment. The above statement illustrates why this paper selected pickleball players' leisure involvement to determine its impact on leisure satisfaction and well-being, and why the leisure satisfaction of pickleball participants has a significant impact on their well-being.

\section{Research Method}

\subsection{Research Structure}

Based on the literature review, and the study objectives and framework of this study, the following hypotheses are outlined, and the research framework is shown in Figure 1.

\subsection{Research Subjects}

Chiu [38] mentioned that a sample size must be larger than 200 persons to be regarded as a medium-sized sample; thus, in order to achieve stable structural equation model analysis results, samples lower than 200 persons are not encouraged. Anderson and Gerbing [39] suggested that the sample size should be at least 100 to 150 when conducting structural equation model studies. In this study, participants of the 2019 International Pickleball NPRP Tournament were selected as the research objects, and 260 pickleball participants were selected as test samples by means of voluntary sampling. A total of 250 pickleball participant questionnaires were recovered, for a recovery rate of $96 \%$. After checking the recovered scales, 35 invalid samples with incomplete questionnaires or fixed 
answers were deleted, leaving 215 valid samples, for an effective questionnaire rate of $80 \%$. The convergence validity of the questionnaire dimensions in this study was verified by combination reliability (C.R.), and average variation extraction (AVE) [40]. Leisure satisfaction and well-being were tested for convergence validity. In addition, bootstrapping was used to examine the confidence interval of Pearson's correlation coefficient between the questionnaire dimensions for discriminant validity testing to ensure the reliability and validity of the questionnaire.

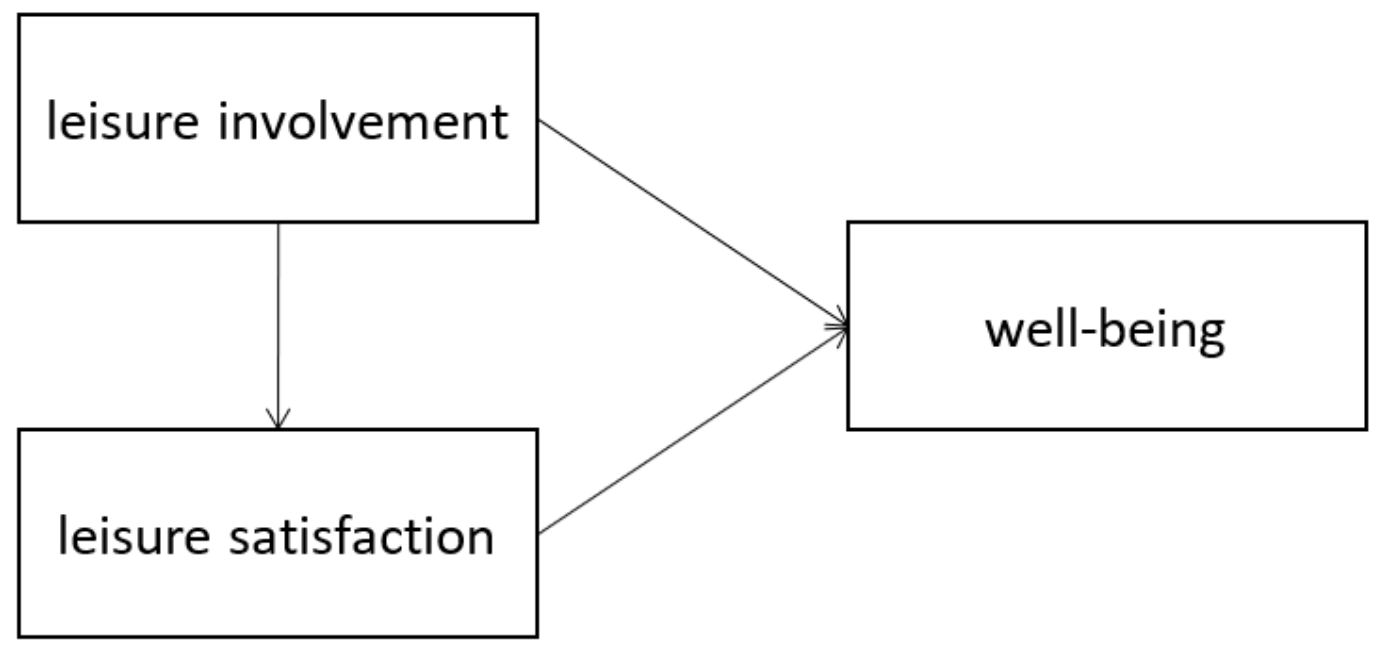

Figure 1. Research framework.

\subsection{Research Tools}

The content of the questionnaire in this study was developed by referring to the relevant literature and questionnaire modifications by [41-43]. The questionnaire was split into 4 sections with 60 questions, including 8 questions on basic personal information, 12 questions on motivation, 19 questions on leisure satisfaction, and 21 questions on wellbeing, in Table A1. A seven-point Likert scale was employed, with each question option being rated from 1 to 7 on a scale of "Strongly disagree" to "Strongly agree", in Table A1.

\subsection{Data Processing and Analysis}

After the questionnaires were collected, and valid questionnaires were counted, invalid questionnaires were excluded. Then, the data were archived using SPSS 24.0 statistical software (IBM, Armonk, NY, USA), and the correlation between variables was analyzed using AMOS 24.0 statistical software (IBM, Armonk, NY, USA).

\section{Research Results}

\subsection{Sample Characteristics}

In this study, there were 215 valid samples. The sample characteristics are shown in Table 1.

\subsection{Measurement Model Analysis}

In this study, the reliability and validity of the questionnaire were tested and analyzed by CFA, and the questionnaire items were revised by the Modification Indices (M.I.) [38]. In total, items A1, A5, A6, and A7 of the Leisure Involvement Scale were deleted; items B6, B7, B13, and B14 of the Leisure Satisfaction Scale were deleted; items C1, C4, C5, C6, C7, C13, C19, C20, and C21 of the Well-being Scale were deleted. 
Table 1. Subjects' characteristics.

\begin{tabular}{|c|c|c|c|c|}
\hline Background Variable & Classification Standard & Sample Size & Percentage $\%$ & Cumulative Percentage $\%$ \\
\hline \multirow{2}{*}{ Gender } & Male & 135 & 62.8 & 62.8 \\
\hline & Female & 80 & 37.2 & 100.0 \\
\hline \multirow{6}{*}{ Age } & 20 years old and below & 39 & 18.1 & 18.1 \\
\hline & $21-30$ years old & 73 & 34.0 & 52.1 \\
\hline & $31-40$ years old & 34 & 15.8 & 67.9 \\
\hline & $41-50$ years old & 29 & 13.5 & 81.4 \\
\hline & $51-60$ years old & 25 & 11.6 & 93.0 \\
\hline & 61 years old and above & 15 & 7.0 & 100.0 \\
\hline \multirow{5}{*}{ Educational level } & Elementary school & 8 & 3.7 & 3.7 \\
\hline & Secondary school & 7 & 3.3 & 7.0 \\
\hline & Vocational high school & 38 & 17.7 & 24.7 \\
\hline & University and college & 133 & 61.9 & 86.5 \\
\hline & $\begin{array}{c}\text { Graduate school (inclusive } \\
\text { and above) }\end{array}$ & 29 & 13.5 & 100.0 \\
\hline \multirow{11}{*}{ Occupation } & Military police & 14 & 6.5 & 6.5 \\
\hline & Civil service staff & 27 & 9.8 & 16.3 \\
\hline & Faculty \& Staff & 37 & 17.2 & 33.5 \\
\hline & $\begin{array}{l}\text { Farming, forestry, fishing, } \\
\text { and herding }\end{array}$ & 8 & 3.7 & 37.2 \\
\hline & Industry & 10 & 4.7 & 41.9 \\
\hline & Manufacturing & 7 & 3.3 & 45.1 \\
\hline & Business & 45 & 20.9 & 66.0 \\
\hline & Services & 24 & 11.2 & 77.2 \\
\hline & Housekeeping & 5 & 2.3 & 79.5 \\
\hline & Students & 31 & 14.4 & 94.0 \\
\hline & Others & 13 & 6.0 & 100.0 \\
\hline \multirow{3}{*}{ Marital status } & Unmarried & 150 & 69.8 & 69.8 \\
\hline & Married & 62 & 28.8 & 98.6 \\
\hline & Others & 3 & 1.4 & 100.0 \\
\hline \multirow{8}{*}{ Teams } & Chinese Taipei & 114 & 53.0 & 53.0 \\
\hline & Japan & 30 & 14.0 & 67.0 \\
\hline & Hong Kong, China & 44 & 20.5 & 87.4 \\
\hline & Singapore & 13 & 6.0 & 93.5 \\
\hline & Korea & 6 & 2.8 & 96.3 \\
\hline & India & 2 & 0.9 & 97.2 \\
\hline & United States & 4 & 1.9 & 99.1 \\
\hline & Others & 2 & 0.9 & 100.0 \\
\hline \multirow{5}{*}{ Participation level } & 2.0 qualifying tournament & 92 & 42.8 & 42.8 \\
\hline & 3.0 qualifying tournament & 47 & 21.9 & 64.7 \\
\hline & Open tournament & 21 & 9.8 & 74.4 \\
\hline & Team competition & 28 & 13.0 & 87.4 \\
\hline & Spectator & 27 & 12.6 & 100.0 \\
\hline \multirow{6}{*}{ Racket price } & NTD 1000 and below & 36 & 16.7 & 16.7 \\
\hline & NTD 1001-2000 & 40 & 18.6 & 35.3 \\
\hline & NTD 2001-3000 & 69 & 32.1 & 67.4 \\
\hline & NTD 3001-4000 & 34 & 15.8 & 83.3 \\
\hline & NTD 4001-5000 & 29 & 13.5 & 96.7 \\
\hline & NTD 5001 and above & 7 & 3.3 & 100.0 \\
\hline
\end{tabular}

\subsubsection{Convergent Validity Test}

The convergent validity of the dimensions in this study was measured by the combined reliability (C.R.), and the average variance extracted (AVE) [40]. Fornell and Larcker [44] suggested that for the purpose of the test, the C.R. value should be greater than 0.6, and the AVE value should be greater than 0.5 . In this study, convergent validity was 
determined from the cognition, motivation, intention, and hindrance dimensions, and the factor loadings for all dimensions ranged from 0.75 to 0.94 . The C.R. values were between 0.78 and 0.94 , and the AVE values were between 0.64 and 0.83 , which met the suggested convergent validity criteria [44-46], indicating that the questionnaire in this study showed positive convergent validity, as shown in Tables 2-4.

Table 2. Leisure involvement-confirmatory analysis.

\begin{tabular}{|c|c|c|c|c|c|c|c|c|c|}
\hline Perspective & Index & $\begin{array}{l}\text { Unstandardized/Standardized } \\
\text { Factor Loading }\end{array}$ & S.E. & C.R. (t-Value) & $p$ & Factor Loading & SMC & C.R. & AVE \\
\hline \multirow{3}{*}{ Attractiveness } & $\mathrm{A} 2$ & 1.00 & & & & 0.89 & 0.79 & 0.92 & 0.80 \\
\hline & A3 & 0.87 & 0.05 & 18.95 & $* * *$ & 0.91 & 0.82 & & \\
\hline & A4 & 0.91 & 0.05 & 18.34 & $* * *$ & 0.89 & 0.79 & & \\
\hline Self & A8 & 1.00 & & & & 0.82 & 0.67 & 0.85 & 0.73 \\
\hline \multirow[t]{2}{*}{ performance } & A9 & 1.05 & 0.08 & 13.79 & $* * *$ & 0.89 & 0.80 & & \\
\hline & A10 & 1.00 & & & & 0.82 & 0.67 & 0.88 & 0.71 \\
\hline \multirow{2}{*}{ Centrality } & A11 & 0.91 & 0.07 & 14.04 & $* * *$ & 0.85 & 0.73 & & \\
\hline & A12 & 0.99 & 0.07 & 14.34 & $* * *$ & 0.86 & 0.74 & & \\
\hline
\end{tabular}

Table 3. Leisure satisfaction-confirmatory analysis.

\begin{tabular}{|c|c|c|c|c|c|c|c|c|c|}
\hline Perspective & Index & $\begin{array}{l}\text { Unstandardized/Standardized } \\
\text { Factor Loading }\end{array}$ & S.E. & C.R. ( $t$-Value) & $p$ & Factor Loading & SMC & C.R. & AVE \\
\hline \multirow[b]{2}{*}{ Self realization } & B1 & 1.00 & & & & 0.92 & 0.84 & 0.90 & 0.81 \\
\hline & B2 & 0.82 & 0.04 & 19.22 & $* * *$ & 0.88 & 0.77 & & \\
\hline \multirow{4}{*}{$\begin{array}{l}\text { Exploring new } \\
\text { knowledge }\end{array}$} & B3 & 1.00 & & & & 0.86 & 0.75 & 0.89 & 0.72 \\
\hline & B4 & 0.99 & 0.06 & 16.89 & $* * *$ & 0.87 & 0.76 & & \\
\hline & B5 & 0.98 & 0.07 & 14.86 & $* * *$ & 0.82 & 0.67 & & \\
\hline & B8 & 1.00 & & & & 0.83 & 0.69 & 0.88 & 0.70 \\
\hline \multirow[t]{2}{*}{ Friendship and care } & B9 & 0.88 & 0.06 & 14.49 & $* * *$ & 0.83 & 0.69 & & \\
\hline & B10 & 1.22 & 0.08 & 14.55 & $* * *$ & 0.85 & 0.72 & & \\
\hline \multirow{2}{*}{$\begin{array}{l}\text { Relaxation of body } \\
\text { and mind }\end{array}$} & B11 & 1.00 & & & & 0.91 & 0.83 & 0.91 & 0.83 \\
\hline & B12 & 0.98 & 0.05 & 21.35 & $* * *$ & 0.91 & 0.83 & & \\
\hline \multirow{2}{*}{ Health and fitness } & B15 & 1.00 & & & & 0.87 & 0.76 & 0.81 & 0.68 \\
\hline & B16 & 1.06 & 0.06 & 19.22 & $* * *$ & 0.94 & 0.88 & & \\
\hline \multirow{3}{*}{$\begin{array}{l}\text { Comfortable } \\
\text { environment }\end{array}$} & B17 & 1.00 & & & & 0.90 & 0.81 & 0.86 & 0.67 \\
\hline & B18 & 0.84 & 0.04 & 20.19 & $* * *$ & 0.90 & 0.81 & & \\
\hline & B19 & 0.93 & 0.04 & 21.34 & $* * *$ & 0.91 & 0.83 & & \\
\hline
\end{tabular}

${ }^{* * *} p<0.001$

\subsubsection{Discriminate Validity}

To test the discriminate validity, a bootstrap method was applied to examine the confidence interval of Pearson's correlation coefficients between the questionnaire dimensions. The results suggested that the confidence interval between the questionnaire dimensions did not contain 1, indicating that the questionnaire dimensions were not perfectly correlated, which means that the discriminant validity of the questionnaire dimensions in this study was statistically significant [45], as detailed in Tables 5-7.

\subsubsection{Structural Model Analysis}

In this study, the overall model fit in the structural model analysis was tested by referring to the seven indicators proposed by Hair et al. [46], and the revised ratio value was 1.19 , which corresponded to the principle that the smaller the ratio of $\chi^{2}$ to the degree of freedom, the better the fit, as pointed out by Bagozzi and Yi [40], and Hair et al. [46], indicated that the closer the GFI and AGFI values are to 1, the better. However, the revised GFI and AGFI values in this study were 0.80 and 0.71, respectively. Bagozzi and Yi [40] suggested that the best RMSEA value is less than 0.08, and the revised RMSEA value in this study was 0.07; the standard value of CFI is better if it is greater than 0.90. In this study, the revised CFI was 0.90 . The PCFI should be at least 0.50 . In this study, the revised PCFI was 0.83 , which demonstrated that the overall fit in this study was good, and all seven 
indicators met the criteria, as shown in Table 8. Figure 2 displays the path analysis results of the relationships among all the constructs.

Table 4. Well-being-confirmatory analysis.

\begin{tabular}{|c|c|c|c|c|c|c|c|c|c|}
\hline Perspective & Index & $\begin{array}{l}\text { Unstandardized } \\
\text { Standardized Factor Loading }\end{array}$ & S.E. & C.R. ( $t$-Value) & $p$ & Factor Loading & SMC & C.R. & AVE \\
\hline \multirow{4}{*}{ Life Satisfaction } & $\mathrm{C} 14$ & 1.00 & & & & 0.86 & 0.73 & 0.94 & 0.79 \\
\hline & C15 & 1.13 & 0.06 & 17.92 & $* * *$ & 0.89 & 0.80 & & \\
\hline & C16 & 1.31 & 0.07 & 17.57 & $* * *$ & 0.89 & 0.79 & & \\
\hline & C17 & 1.20 & 0.06 & 18.48 & $* * *$ & 0.91 & 0.83 & & \\
\hline \multirow{2}{*}{ Identity affirmation } & $\mathrm{C} 2$ & 1.00 & & & & 0.92 & 0.84 & 0.89 & 0.80 \\
\hline & $\mathrm{C} 3$ & 0.86 & 0.05 & 17.88 & $* * *$ & 0.87 & 0.76 & & \\
\hline \multirow{4}{*}{$\begin{array}{l}\text { Interpersonal } \\
\text { relationship }\end{array}$} & $\mathrm{C} 8$ & 1.00 & & & & 0.87 & 0.76 & 0.93 & 0.77 \\
\hline & C9 & 1.07 & 0.06 & 18.24 & $* * *$ & 0.89 & 0.79 & & \\
\hline & C10 & 0.91 & 0.05 & 17.37 & $* * *$ & 0.87 & 0.75 & & \\
\hline & C11 & 1.06 & 0.06 & 18.33 & $* * *$ & 0.89 & 0.80 & & \\
\hline \multirow{2}{*}{$\begin{array}{l}\text { Physical and } \\
\text { mental health }\end{array}$} & $\mathrm{C} 12$ & 1.00 & & & & 0.85 & 0.73 & 0.78 & 0.64 \\
\hline & C18 & 0.75 & 0.06 & 12.35 & $* * *$ & 0.75 & 0.56 & & \\
\hline
\end{tabular}

Table 5. Leisure involvement bootstrap 95\% confidence interval table of related coefficients.

\begin{tabular}{cccccccc}
\hline & & & \multicolumn{3}{c}{ Bias-Corrected } & \multicolumn{3}{c}{ Percentile Method } \\
\cline { 4 - 8 } & & & Estimate & $\begin{array}{c}\text { Lower } \\
\text { Boundary }\end{array}$ & $\begin{array}{c}\text { Upper } \\
\text { Boundary }\end{array}$ & $\begin{array}{c}\text { Lower } \\
\text { Boundary }\end{array}$ & $\begin{array}{c}\text { Upper } \\
\text { Boundary }\end{array}$ \\
\hline Attractiveness & $<->$ & Self performance & 0.77 & 0.65 & 0.87 & 0.66 & 0.87 \\
Attractiveness & $<->$ & Centrality & 0.72 & 0.59 & 0.81 & 0.61 & 0.82 \\
Self performance & $<->$ & Centrality & 0.80 & 0.61 & 0.98 & 0.62 & 0.99 \\
\hline
\end{tabular}

Table 6. Leisure satisfaction bootstrap 95\% confidence interval table of related coefficients.

\begin{tabular}{|c|c|c|c|c|c|c|c|}
\hline & & & \multicolumn{3}{|c|}{ Bias-Corrected } & \multicolumn{2}{|c|}{ Percentile Method } \\
\hline & & & Estimate & $\begin{array}{c}\text { Lower } \\
\text { Boundary }\end{array}$ & $\begin{array}{c}\text { Upper } \\
\text { Boundary }\end{array}$ & $\begin{array}{c}\text { Lower } \\
\text { Boundary }\end{array}$ & $\begin{array}{c}\text { Upper } \\
\text { Boundary }\end{array}$ \\
\hline Self realization & $<->$ & $\begin{array}{l}\text { Exploring new } \\
\text { knowledge }\end{array}$ & 0.92 & 0.85 & 0.96 & 0.86 & 0.97 \\
\hline Self realization & $<->$ & Friendship and care & 0.85 & 0.79 & 0.91 & 0.79 & 0.91 \\
\hline Self realization & $<->$ & $\begin{array}{l}\text { Relaxation of body } \\
\text { and mind }\end{array}$ & 0.88 & 0.82 & 0.93 & 0.82 & 0.93 \\
\hline Self realization & $<->$ & Health and fitness & 0.82 & 0.74 & 0.87 & 0.75 & 0.88 \\
\hline Self realization & $<->$ & $\begin{array}{l}\text { Comfortable } \\
\text { environment }\end{array}$ & 0.89 & 0.84 & 0.93 & 0.85 & 0.93 \\
\hline $\begin{array}{l}\text { Exploring new } \\
\text { knowledge }\end{array}$ & $<->$ & Friendship and care & 0.86 & 0.76 & 0.94 & 0.77 & 0.95 \\
\hline $\begin{array}{l}\text { Exploring new } \\
\text { knowledge }\end{array}$ & $<->$ & $\begin{array}{c}\text { Relaxation of body } \\
\text { and mind }\end{array}$ & 0.87 & 0.82 & 0.92 & 0.82 & 0.92 \\
\hline $\begin{array}{l}\text { Exploring new } \\
\text { knowledge }\end{array}$ & $<->$ & Health and fitness & 0.85 & 0.78 & 0.90 & 0.79 & 0.90 \\
\hline $\begin{array}{l}\text { Exploring new } \\
\text { knowledge }\end{array}$ & $<->$ & $\begin{array}{l}\text { Comfortable } \\
\text { environment }\end{array}$ & 0.82 & 0.75 & 0.88 & 0.76 & 0.88 \\
\hline Friendship and care & $<->$ & $\begin{array}{l}\text { Relaxation of body } \\
\text { and mind }\end{array}$ & 0.92 & 0.84 & 0.96 & 0.85 & 0.97 \\
\hline Friendship and care & $<->$ & Health and fitness & 0.78 & 0.69 & 0.85 & 0.70 & 0.86 \\
\hline Friendship and care & $<->$ & $\begin{array}{l}\text { Comfortable } \\
\text { environment }\end{array}$ & 0.80 & 0.71 & 0.87 & 0.71 & 0.88 \\
\hline $\begin{array}{l}\text { Relaxation of body } \\
\text { and mind }\end{array}$ & $<->$ & Health and fitness & 0.88 & 0.81 & 0.93 & 0.81 & 0.93 \\
\hline $\begin{array}{l}\text { Relaxation of body } \\
\text { and mind }\end{array}$ & $<->$ & $\begin{array}{l}\text { Comfortable } \\
\text { environment }\end{array}$ & 0.92 & 0.87 & 0.96 & 0.87 & 0.96 \\
\hline Health and fitness & $<->$ & $\begin{array}{l}\text { Comfortable } \\
\text { environment }\end{array}$ & 0.84 & 0.78 & 0.90 & 0.78 & 0.90 \\
\hline
\end{tabular}


Table 7. Well-being bootstrap 95\% confidence interval table of related coefficients.

\begin{tabular}{|c|c|c|c|c|c|c|c|}
\hline & & & \multicolumn{3}{|c|}{ Bias-Corrected } & \multicolumn{2}{|c|}{ Percentile Method } \\
\hline & & & Estimate & $\begin{array}{c}\text { Lower } \\
\text { Boundary }\end{array}$ & $\begin{array}{l}\text { Upper } \\
\text { Boundary }\end{array}$ & $\begin{array}{c}\text { Lower } \\
\text { Boundary }\end{array}$ & $\begin{array}{c}\text { Upper } \\
\text { Boundary }\end{array}$ \\
\hline Life Satisfaction & $<->$ & $\begin{array}{c}\text { Identity } \\
\text { affirmation }\end{array}$ & 0.66 & 0.50 & 0.81 & 0.51 & 0.82 \\
\hline Life Satisfaction & $<->$ & $\begin{array}{l}\text { Interpersonal } \\
\text { relationship }\end{array}$ & 0.70 & 0.53 & 0.84 & 0.54 & 0.85 \\
\hline Life Satisfaction & $<->$ & $\begin{array}{l}\text { Physical and } \\
\text { mental health }\end{array}$ & 0.91 & 0.84 & 0.98 & 0.84 & 0.98 \\
\hline Identity affirmation & $<->$ & $\begin{array}{l}\text { Interpersonal } \\
\text { relationship }\end{array}$ & 0.91 & 0.79 & 0.99 & 0.80 & 0.99 \\
\hline Identity affirmation & $<->$ & $\begin{array}{l}\text { Physical and } \\
\text { mental health }\end{array}$ & 0.72 & 0.51 & 0.93 & 0.52 & 0.95 \\
\hline Interpersonal relationship & $<->$ & $\begin{array}{l}\text { Physical and } \\
\text { mental health }\end{array}$ & 0.75 & 0.52 & 0.96 & 0.53 & 0.97 \\
\hline
\end{tabular}

Table 8. Structural model.

\begin{tabular}{cccc}
\hline Model Fit Index & Recommended Value & Measurement Values & Remarks \\
\hline$\chi^{2}$ (Chi-squared) & & 1286.53 & \\
$\chi^{2} / \mathrm{df}$ & $<3$ & 2.36 & accepted \\
GFI & $>0.80$ & 0.80 & accepted \\
AGFI & $>0.80$ & 0.71 & accepted \\
RMSEA & $<0.08$ & 0.07 & accepted \\
CFI & $>0.90$ & 0.90 & accepted \\
PCFI & $>0.50$ & 0.83 & accepted \\
\hline
\end{tabular}

Table 9 shows that in the leisure involvement $\rightarrow$ leisure satisfaction $\rightarrow$ well-being indirect effect (0.557), the confidence interval (BC: 0.469-0.666, PC: 0.453-0.650) does not contain 0 , which reaches a significant effect $(p<0.01)$, and shows that leisure satisfaction has a mediating effect. In the leisure involvement $\rightarrow$ leisure satisfaction direct effect (0.775), the confidence interval (BC: 0.660-0.846, PC: 0.672 0.849) contains 0, which means a significant effect. In the leisure satisfaction $\rightarrow$ well-being direct effect (0.148), the confidence interval (BC: 0.568 0.823, PC: 0.029 0.303) does not contain 0, which means a significant effect. In the leisure involvement $\rightarrow$ well-being direct effect $(0.001)$, the confidence interval (BC: 0.029 0.300, PC: $0.023 \sim 0.019)$ does not contain 0 , which means a significant effect. The total effect (0.706) and confidence interval (BC: 0.589 0.795, PC: 0.594 0.798), which reaches a significant effect, means that leisure satisfaction in leisure involvement and well-being are completely mediating effects, according to [47-49].

Table 9. Mediating effect.

\begin{tabular}{|c|c|c|c|c|}
\hline \multirow{2}{*}{ Indirect Effect } & \multirow{2}{*}{ Estimate } & \multicolumn{3}{|c|}{ 95\% Confidence Interval } \\
\hline & & BC/PC $p$ Value & BC & PC \\
\hline $\begin{array}{c}\text { Leisure Involvement } \rightarrow \text { Leisure Satisfaction } \\
\qquad \begin{array}{c}\rightarrow \text { Well-being } \\
\text { Direct effect }\end{array}\end{array}$ & 0.557 & $0.000 / 0.001$ & $0.469 \sim 0.666$ & $0.453 \sim 0.650$ \\
\hline Leisure Involvement $\rightarrow$ Leisure Satisfaction & 0.775 & $0.002 / 0.001$ & $0.660 \sim 0.846$ & $0.672 \sim 0.849$ \\
\hline Leisure Satisfaction $\rightarrow$ Well-being & 0.719 & $0.023 / 0.019$ & $0.568 \sim 0.823$ & $0.029 \sim 0.303$ \\
\hline $\begin{array}{c}\text { Leisure Involvement } \rightarrow \text { Well-being } \\
\text { Total effect }\end{array}$ & 0.148 & $0.024 / 0.300$ & $0.029 \sim 0.300$ & $0.023 \sim 0.019$ \\
\hline Leisure Involvement $\rightarrow$ Well-being & 0.706 & $0.001 / 0.001$ & $0.589 \sim 0.795$ & $0.594 \sim 0.798$ \\
\hline
\end{tabular}




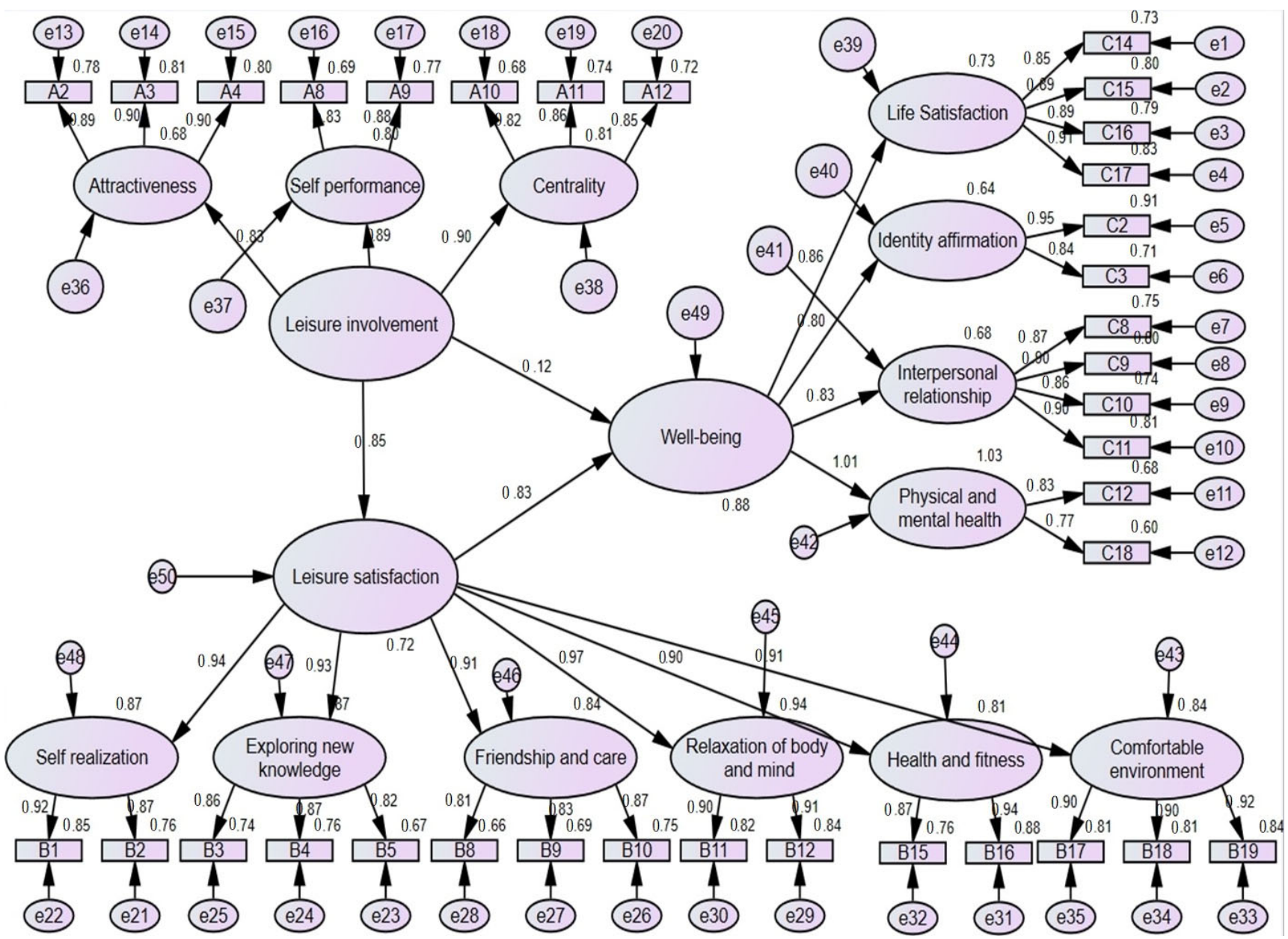

Figure 2. Model of the effect of leisure involvement and leisure satisfaction on the well-being of pickleball players.

$\mathrm{H} 1$ is supported. That is, leisure involvement has a significant effect on leisure satisfaction, which is the same conclusion as Chen, $\mathrm{Li}$, and Chen [28]. It is possible that when pickleball is highly attractive to players, they invest more in related skills and equipment, which, in turn, increases leisure satisfaction. $\mathrm{H} 2$ is rejected. That is, leisure involvement does not have a significant effect on well-being, which is unlike the findings of Mehmet [32]. A possible factor is that although pickleball players put a lot of effort into the sport, wellbeing is an overall life satisfaction assessment; therefore, it is likely that some parts of their lives, other than participation in pickleball, are not satisfying, which affects their assessment of well-being. $\mathrm{H} 3$ is supported. That is, leisure satisfaction has a significant effect on well-being, which echoes the findings of Kaya [35]. As mentioned above, well-being is an assessment of overall life satisfaction. When pickleball players feel that the gap between their actual performance and their goals is small, they are likely to be satisfied with their physical, psychological, and social benefits, thereby scoring higher in their assessment of well-being. H4 is supported, which indicates that the leisure satisfaction of pickleball participants has a complete mediating effect on the relationship between leisure involvement and well-being. In other words, leisure involvement not only directly affects well-being, but also indirectly affects well-being through leisure satisfaction, and this conclusion is similar to the research conclusion of [36].

\section{Conclusions and Suggestions}

\subsection{Conclusions}

With the establishment of the Chinese Taipei Pickleball Association in November 2016, people in Chinese Taipei are becoming more aware of this popular sport that flourishes 
in the U.S. In the future, after more pickleball-related clubs and organizations are formed, pickleball will be more popularized in elementary and middle schools, high school clubs, and university physical education programs. Moreover, this sport is suitable for seniors to participate in, which will encourage the popularization of pickleball. Due to the differences in the degree of involvement of pickleball players, how to improve the participants' wellbeing and leisure satisfaction through participation in pickleball will be a matter of concern for the future promotion of organizations. This study focused on the effect of leisure involvement and leisure satisfaction on well-being by taking pickleball players as the subjects. Through analysis of the empirical data, the following main findings are drawn from this study:

(1) H1 is supported, i.e., leisure involvement has a significant effect on leisure satisfaction.

(2) H2 is rejected, i.e., leisure involvement does not have a significant effect on well-being.

(3) H3 is supported, i.e., leisure satisfaction has a significant effect on well-being.

(4) H4 is supported, i.e., leisure satisfaction has an intermediary effect on the relationship between leisure involvement and well-being.

\subsection{Suggestions}

Based on the results, this study proposes the following suggestions for reference:

\subsubsection{For Pickleball Players}

As the results of this study show that leisure involvement has a significant effect on leisure satisfaction, it is suggested that pickleball players can seek to increase their level of leisure involvement; for example, by strengthening their social bonds. Especially nowadays, given the popularity of and access to social media, many sports associations share professional knowledge about pickleball and tournament information, and provide a forum for players to communicate with each other. Therefore, through social media, every pickleball fan can share, respond, interact, and communicate with others, which is far beyond the one-way communication of the past. As such, seeking to join a pickleballrelated community will help to enhance social bonding, and deepen the involvement in the sport; for example, the dedicated fan page of the Chinese Taipei Pickleball Association provides information on tournament announcements, tips for beginners, training events, tactics, and game videos. Interactions with fellow players facilitate the sharing of relevant skills information and training knowledge, and allow fellow players to meet and build stronger social connections, thus, raising the level of leisure involvement. Moreover, in order to make pickleball a central part of life, and ensure that various factors, such as family, school, or work, do not impede participation, it is recommended that pickleball enthusiasts manage their free time well to free up more time for the sport. For example, advance planning can enhance the use of free time. An actual participation strategy can include gradually developing one's skills in the game of pickleball, participating in tournaments at a level that matches one's ability, and expanding one's network from there. Chen, $\mathrm{Ma}, \mathrm{Yu}$, and Chiu [37] hold the same view, suggesting that players who participate in tournaments will gradually become long-term participants of pickleball, which will greatly increase the participation population of pickleball. By playing in tournaments, participants can relax muscles and bones, slow down aging, strengthen their body functions, increase social activities, maintain interpersonal interactions, and enhance the abundance of the mind, which would also facilitate strengthening one's game knowledge. By planning ahead in this way, the barriers to participation in pickleball are further reduced, and the level of involvement in the sport is increased for a better leisure experience.

Overall, pickleball is a racquet sport that combines tennis, badminton, and table tennis. Pickleball is a new and rapidly growing sport in the United States, and because it only requires a short time to learn the game, it is suitable for people who have no sports experience, and is of particular interest for people who have played tennis, table tennis, and badminton. In terms of physical activity, pickleball is suitable for all ages [16]. In this study, the influence of leisure involvement and leisure satisfaction on the well-being of pickleball 
participants was taken as the investigation element. Therefore, the direction of future efforts will focus on how to understand activity planning for increased participation in pickleball, as well as in-depth analysis of the benefits of participation in pickleball, in order to widely promote it to the public and other countries, move towards internationalization, and become a leisure sport with sustainable global participation in the future.

\subsubsection{For the Main Organizers of the Tournament}

The results of this study show that leisure satisfaction has a significant effect on well-being, hence this paper suggests that organizers can take steps to improve players' satisfaction. In particular, as leisure satisfaction involves psychological, social, physiological, and aesthetic aspects, organizers can allocate personnel according to the scale of the tournament. Some tournaments are large in scale and require a variety of roles to complete the related tasks, whereas some tournaments may be simpler and require only a few personnel to perform; for example, the scale of the 2020 Asian Open and the 2020 Taichung Mayor's Cup Pickleball Tournament were of different levels. The former demanded much more human resources than the latter, and the former placed higher demands on athletes' accommodation, entry and exit, documentation, catering, transportation, security, and courtesy. In any case, when the right people are placed in the right places, it will ensure the participants' satisfaction with the event. Once participants are satisfied psychologically and physically, they will be able to devote themselves to the event. Chen, Yuan, and Hsieh [50] put forward a similar point of view, and considered that pickleball event organizers or shotlighting units can choose venues with convenient transportation and perfect, comfortable, and safe course equipment to conduct experiential activities or competitions. They can also offer promotions, such as a discount scheme for registration fees if they sign up with family members or friends. In this way, the obstacles of pickleball participants to access this leisure sport can be reduced, and the leisure satisfaction of pickleball participants can be improved.

In addition, enhancing the aesthetic level of the event will improve the leisure satisfaction of participants, starting with the entertainment experience of the event, and considering the venue layout, video feeds, award ceremony, broadcasting screens, music, and event commentators.

Needless to say, one of the most crucial parts of running a tournament is planning the best venue for the athletes to participate in, and coordinating with all responsible parties to ensure the highest level of venue operation during the tournament; for example, regarding venue selection, it is necessary to confirm whether the space and facilities comply with the specifications of the pickleball organization. Under the impact of the pandemic, proper arrangements for pandemic prevention and route planning during the tournament can enhance the satisfaction of participants.

In addition, since the leisure satisfaction of pickleball participants has a significant impact on well-being, it is suggested that organizers can also use such relationships to promote pickleball. As Hsu, Lu, and Wang [16] pointed out, participants generally consider that obstacles to the development of pickleball are due to the lack of pickleball friends, insufficient coaches and professional referees, insufficient courts, and a low choice of pickleball equipment. Moreover, as pickleball has only recently been introduced in Taiwan, it is difficult to find pickleball friends, and there are few coaches, venues, or purchasing choices for related equipment. Therefore, it is suggested that organizers organize events that encourage the public to participate in pickleball through relevant strategies; for example, during the event, the venue can provide equipment introduction and selling services to provide the general public with more access to suitable equipment. In addition, an organizer can set up a special fan page to share information related to the event and teaching resources, or even become a platform for pickleball friends to communicate. Such measures and promotions could ensure that everyone who wants to participate in pickleball can have the opportunity to contact the sport to improve their leisure satisfaction, and further improve their well-being. 


\subsubsection{Future Research Suggestions}

1. The motivations of those who regard pickleball as a recreational activity, and those who regard pickleball as a competition are certainly different. Since this study focused on pickleball as a competition, future studies can analyze the above two different types of participants through the two related theories of Serious Leisure and Peak Experience.

2. The PCM Model by James [51] divided participants' psychological connection and identification mechanism for sports into four stages: awareness, attraction, attachment, and allegiance. Regarding the development of pickleball, this model can indeed further discuss the participants' participation process, especially as pickleball is still in the awareness stage at present. In particular, as pickleball events are rarely held, and related media reports are few, it is difficult for participants to enter the attraction stage. Therefore, further empirical analysis based on the PCM model (psychological continuity model) will help to explore the participation process of participants, and provide opportunities for more discussion and verification of attachment and allegiance.

3. With the advancement of technology, a number of tournaments have introduced technology for more accurate judging; for example, four major tennis open tournaments have adopted Hawk-Eye as a more accurate judging method. In addition, the future application of artificial intelligence in sporting events may become a trend; for example, the "Tsinghai Sports Technology Center" established by Tsing Hua University focuses on promoting the Tisa Baseball Project, where the strategy is to put sensors into baseball balls to record the trajectory, ball rotation speed, and the force and angle of the pitcher's ball control. As such data can facilitate the improvement of players and the standard of play, the future developments of pickleball and related events will be more associated with technology. Accordingly, regarding future research suggestions, relevant theories can be utilized to explore relevant issues; for example, the technology acceptance model is one of the theoretical bases to be explored, i.e., empirical research on pickleball players' perceptions of the usefulness and ease of use of tournament-related technology. The results of this study will help to expand the discussion beyond the leisure behavior of pickleball players, and may improve the quality of pickleball tournaments due to the introduction of technology, which, in turn, may boost the leisure satisfaction of the participants. However, as pickleball has not been formally introduced in Chinese Taipei as other popular sports have been, the number of participants is relatively small, and it was relatively difficult to obtain samples for this study. It is suggested that in-depth interviews be conducted with the players in order to further examine the obstacles to the development of pickleball by integrating the interviewees' opinions, as in-depth interviews will highlight issues other than structural barriers (e.g., lack of coaches and professional referees, and insufficient courts).

Author Contributions: Conceptualization, Q.C. and C.Y.C.; Data curation, C.Y.C.; Formal analysis, Q.C.; Investigation, C.-C.C.; Methodology, C.-C.C. and J.-W.L.; Project administration, J.-W.L. and C.-H.H.; Supervision, C.-H.H. All authors have read and agreed to the published version of the manuscript.

Funding: This research received no external funding.

Institutional Review Board Statement: We have applied for an introspective Institution Review Board approval (Wuhan Sports University \& Hospital Research Ethics Center).

Informed Consent Statement: We referred to the research ethics declaration when editing the questionnaire survey manual, and during the interview process, the questionnaire tool was used to compile a survey manual for interviewees to read.

Data Availability Statement: No data support.

Conflicts of Interest: The authors declare no conflict of interest. 


\section{Appendix A}

Table A1. Questionnaire on the effect of leisure involvement and leisure satisfaction on the well-being of pickleball players.

\begin{tabular}{|c|c|}
\hline Dimension & Contents \\
\hline Attractiveness & $\begin{array}{l}\text { 1. I often discuss pickleball with my friends. } \\
\text { 2. Pickleball is a very important leisure activity for me. } \\
\text { 3. Pickleball is one of the activities that make me feel most satisfied. } \\
\text { 4. Pickleball is one of the most fun activities for me. } \\
\text { 5. Pickleball can relieve my stress. }\end{array}$ \\
\hline Self performance & $\begin{array}{l}\text { 6. I like to introduce pickleball to others whenever I have the opportunity. } \\
\text { 7. I hope others will regard me as a veteran in pickleball. } \\
\text { 8. I regard pickleball as a special skill and am proud of it. } \\
\text { 9. I think pickleball is an indispensable activity in my life. }\end{array}$ \\
\hline Centrality & $\begin{array}{l}\text { 10. Most of my close friends are pickleball players. } \\
\text { 11. I think pickleball can create a unique image of self. } \\
\text { 12. I find that my daily life is closely related to pickleball. }\end{array}$ \\
\hline Self realization & $\begin{array}{l}\text { 1. Participating in the } 2019 \text { International Pickleball NPRP Tournament gave } \\
\text { me confidence. } \\
\text { 2. Participating in the } 2019 \text { International Pickleball NPRP Tournament gave me a sense } \\
\text { of achievement. }\end{array}$ \\
\hline Exploring new knowledge & $\begin{array}{l}\text { 3. Participating in the } 2019 \text { International Pickleball NPRP Tournament helped me } \\
\text { broaden my knowledge. } \\
\text { 4. Participating in the } 2019 \text { International Pickleball NPRP Tournament helped me try } \\
\text { new things. } \\
\text { 5. Participating in the } 2019 \text { International Pickleball NPRP Tournament helped me } \\
\text { understand myself. } \\
\text { 6. Participating in the } 2019 \text { International Pickleball NPRP Tournament helped me get } \\
\text { to know others. } \\
\text { 7. I had social interactions with others by participating in the } 2019 \text { International } \\
\text { Pickleball NPRP Tournament. }\end{array}$ \\
\hline Friendship and care & $\begin{array}{l}\text { 8. Participating in the } 2019 \text { International Pickleball NPRP Tournament helped me } \\
\text { make intimate friends. } \\
\text { 9. All the people I met when participating in the } 2019 \text { International Pickleball NPRP } \\
\text { Tournament were friendly. } \\
\text { 10. In my spare time, I often associate with people who know how to enjoy } \\
\text { leisure sports. }\end{array}$ \\
\hline Relaxation of body and mind & $\begin{array}{l}\text { 11. Participating in the } 2019 \text { International Pickleball NPRP Tournament helped } \\
\text { me relax. } \\
\text { 12. Participating in the } 2019 \text { International Pickleball NPRP Tournament helped me } \\
\text { relieve stress. } \\
\text { 13. Participating in the } 2019 \text { International Pickleball NPRP Tournament was conducive } \\
\text { to my emotional health. }\end{array}$ \\
\hline Health and fitness & $\begin{array}{l}\text { 14. Participating in the } 2019 \text { International Pickleball NPRP Tournamentwas very } \\
\text { challenging for my physical fitness. } \\
\text { 15. Participating in the } 2019 \text { International Pickleball NPRP Tournament increased my } \\
\text { physical fitness. } \\
\text { 16. Participating in the } 2019 \text { International Pickleball NPRP Tournament helped me } \\
\text { stay healthy. }\end{array}$ \\
\hline Comfortable environment & $\begin{array}{l}\text { 17. The places or areas where I participated in the } 2019 \text { International Pickleball NPRP } \\
\text { Tournament were clean and tidy. } \\
\text { 18. The places or regions where I participated in the } 2019 \text { International Pickleball } \\
\text { NPRP Tournament were interesting. } \\
\text { 19. The places or regions where I participated in the } 2019 \text { International Pickleball } \\
\text { NPRP Tournament were beautiful. }\end{array}$ \\
\hline
\end{tabular}


Table A1. Cont.

Dimension

Life Satisfaction

Identity affirmation

\section{Contents}

1. In the process of participating in the 2019 International Pickleball NPRP

Tournament, I thought that I am attractive.

2. In the process of participating in the 2019 International Pickleball NPRP

Tournament, I had great confidence in myself.

3. I felt energetic in the process of participating in the 2019 International Pickleball NPRP Tournament.

4. In the process of participating in the 2019 International Pickleball NPRP

Tournament, I felt that life is meaningful and has goals.

5. In the process of participating in the 2019 International Pickleball NPRP

Tournament, I liked my life.

6. In the process of participating in the 2019 International Pickleball NPRP

Tournament, I thought that I am very happy.

7. In the process of participating in the 2019 International Pickleball NPRP

Tournament, I could bring happiness to others.

8. In the process of participating in the 2019 International Pickleball NPRP

Tournament, I was interested in caring about other people's affairs.

9. I liked to help others in the process of participating in the 2019 International

Pickleball NPRP Tournament.

10. In the process of participating in the 2019 International Pickleball NPRP

Tournament, I felt very happy with my friends.

11. In the process of participating in the 2019 International Pickleball NPRP

Tournament, my participation made things better.

12. I could control my life in the process of participating in the 2019 International

Pickleball NPRP Tournament.

13. In the process of participating in the 2019 International Pickleball NPRP Tournament, my ideals could be realized.

14. In the process of participating in the 2019 International Pickleball NPRP

Tournament, I thought that things in the world are beautiful.

15. In the process of participating in the 2019 International Pickleball NPRP

Tournament, I thought that life is satisfactory.

16. In the process of participating in the 2019 International Pickleball NPRP

Tournament, I thought that my life is better than others.

17. I had a good impact on everything in my life when I participated in the 2019

International Pickleball NPRP Tournament.

18. In the process of participating in the 2019 International Pickleball NPRP

Tournament, I was in good health.

19. In the process of participating in the 2019 International Pickleball NPRP

Tournament, I often kept a relaxed mood.

\section{References}

1. Ryu, J.; Yang, H.; Kim, A.C.H.; Kim, K.M.; Heo, J. Understanding pickleball as a new leisure pursuit among older adults. Educ. Gerontol. 2018, 44, 128-138. [CrossRef]

2. Wray, P.; Ward, C.K.; Nelson, C.; Sulzer, S.H.; Dakin, C.J.; Thompson, B.J.; Vierimaa, M.; Das Gupta, D.; Bolton, D.A.E. Pickleball for Inactive Mid-Life and Older Adults in Rural Utah: A Feasibility Study. Int. J. Environ. Res. Public Health 2021, 18, 8374. [CrossRef]

3. Chang, C.H. Feasibility Assessment of Introducing Pickleball to Older Adults. Master's Thesis, Department of Leisure and Recreation Management, Asia University, Taichung City, China, 2018.

4. Chang, S.; Gibson, H. Physically Active Leisure and Tourism Connection: Leisure Involvement and Choice of Tourism Activities among Paddlers. Leis. Sci. 2011, 33, 162-181. [CrossRef]

5. Beard, J.G.; Ragheb, M.G. Measuring leisure satisfaction. J. Leis. Res. 1980, 12, 20-33. [CrossRef]

6. Keung, B.; Goswami, R. Children's subjective well-being: International comparative perspectives. Child Incl. Res. $2011,33,548-556$.

7. Heo, J.; Ryu, J.; Yang, H.; Kim, K.M. Serious leisure and depression in older adults: A study of pickleball players. Leis. Stud. 2018, 37, 561-573. [CrossRef]

8. Casper, J.M.; Jeon, J.H. Psychological Connection to Pickleball: Assessing Motives and Participation in Older Adults. J. Aging Phys. Act. 2018, 27, 28-33. [CrossRef] 
9. Heo, J.; Ryu, J.; Yang, H.; Kim, A.C.H.; Rhee, Y. Importance of playing pickleball for older adults' subjective well-being: A serious leisure perspective. J. Posit. Psychol. 2018, 13, 67-77. [CrossRef]

10. Buzzelli, A.A.; Draper, J.A. Examining the motivation and perceived benefits of pickleball participation in older adults. J. Aging Phys. Act. 2019, 28, 180-186. [CrossRef]

11. Greiner, N. Pickleball: Injury considerations in an increasingly popular sport. Mo. Med. 2019, 116, 488-491.

12. Quail, M.T. Caring for patients with pickleball injuries. Nursing 2019, 49, 16-17. [CrossRef] [PubMed]

13. Mathias, B.; Forrester, B.S. Pickleball-Related Injuries Treated in Emergency Departments. J. Emerg. Med. 2020, 58, $275-279$.

14. James, Z. "You Dinked My Battleship": The Dinking Game for Pickleball Skill Learning. Strategies 2019, $32,22-28$.

15. USA Pickleball Association. History of the Game. Available online: https://www.usapa.org/history-of-the-game/ (accessed on 9 September 2021).

16. Hsu, F.C.; Lu, C.T.; Wang, L.L. Exploring Pickle ball Participation and Acceptance of Older Adults in Taiwan. J. Gerontechnol. Serv. Manag. 2018, 6, 389-400.

17. Havitz, M.E.; Dimanche, F. Leisure involvement revisited: Conceptual conundrums and measurement advances. J. Leis. Res. 1997, 29, 245-278. [CrossRef]

18. Godbey, G. Leisure in Your Life: An Exploration; Venture Publishing: State College, PA, USA, 2003.

19. Kyle, G.; Graefe, A.; Manning, R.; Bacon, J. Effect of activity involvement and place attachment on recreationists' perception of setting density. J. Leis. Res. 2004, 3, 209-231. [CrossRef]

20. Jackson, E.L.; Crawford, D.W.; Godbey, G. Negotiation of leisure constraints. Leis. Sci. 1993, 15, 1-11. [CrossRef]

21. Agyar, E. Contribution of perceived freedom and leisure satisfaction to life satisfaction in a sample of Turkish women. Soc. Indic. Res. 2014, 116, 1-15. [CrossRef]

22. Mannell, R.C.; Kleiber, D.A. A Social Psychology of Leisure; Venture Publishing Inc.: State College, PA, USA, 1997.

23. Ryff, C.D. Happiness is everything, or is it? Explorations on the meaning of psychological well-being. J. Personal. Soc. Psychol. 1989, 57, 1069-1081. [CrossRef]

24. Brajša-Žganec, A.; Merkaš, M.; Šverko, I. Quality of life and leisure activities: How do leisure activities contribute to subjective well-being? Soc. Indic. Res. 2011, 102, 81-91. [CrossRef]

25. Kuykendall, L.; Tay, L.; Ng, V. Leisure engagement and subjective well-being: A meta-analysis. Psychol. Bull. 2015, 141, 364-403. [CrossRef] [PubMed]

26. Rees, G. Children's Leisure Activities and Subjective Well-Being: A Comparative Analysis of 16 Countries. In Handbook of Leisure, Physical Activity, Sports, Recreation and Quality of Life. International Handbooks of Quality-of-Life; de la Vega, L.R., Toscano, W., Eds.; Springer: Cham, Switzerland, 2018.

27. Trainor, S.; Delfabbro, P.; Anderson, S.; Winefield, A. Leisure activities and adolescent psychological well-being. J. Adolesc. 2010, 33, 173-186. [CrossRef] [PubMed]

28. Chen, Y.C.; Li, R.H.; Chen, S.H. Relationships among Adolescents' Leisure Motivation, Leisure Involvement, and Leisure Satisfaction: A Structural Equation Model. Soc. Indic. Res. 2013, 110, 1187-1199. [CrossRef]

29. Tsai, M.H.; Guo, Y.K. The Relationship among Leisure Motivation, Leisure Involvement and Satisfaction of Elders. J. Tour. Leis. Manag. 2016, 4, 119-128.

30. Pan, S.L.; Wu, H.C.; Morrison, A.M.; Huang, M.T.; Huang, W.S. The Relationships among Leisure Involvement, Organizational Commitment and Well-Being: Viewpoints from Sports Fans in Asia. Sustainability 2018, 10, 740. [CrossRef]

31. Lo, C.F. A Study of Relationship among the Leisure Involvement, Leisure Satisfaction and Well-Being in Senior Citizens. Master's Thesis, Department of Travel Management, Jinwen University of Science and Technology, New Taipei City, China, 2020.

32. Mehmet, D. Leisure Involvement and Happiness Levels of Individuals Having Fitness Center Membership. J. Educ. Learn. 2019, $8,140-149$

33. Spiers, A.; Walker, G.J. The effects of ethnicity and leisure satisfaction on happiness, peacefulness, and quality of life. Leis. Sci. 2009, 31, 84-99. [CrossRef]

34. Liu, H. Personality, Leisure Satisfaction, and Subjective Well-Being of Serious Leisure Participants. Soc. Behav. Person. Int. J. 2014, 42, 1117-1125. [CrossRef]

35. Kaya, S. The Relationship between Leisure Satisfaction and Happiness among College Students. J. Educ. Res. $2016,4,622-631$. [CrossRef]

36. Huang, M.F. A Study of Relationship between Leisure Participation Motivation and Well-Being for Employees of State-Owned Enterprises: The Intermediary Role of Leisure Satisfaction. Master's Thesis, Department of Tourism Management, Chinese Culture University, Taipei, China, 2014.

37. Chen, C.C.; Ma, H.C.; Yu, C.H.; Chiu, W.S. Research on pickleball rating tournament Taiwan. J. Sport Recreat. Res. 2021, 15, 41-59.

38. Chiu, H.C. Quantitative Research and Statistical Analysis: Analysis of Data Analysis Examples of SPSS Chinese Window Version; Wu Nan Books: Taipei City, China, 2006.

39. Anderson, J.; Gerbing, D. Structural equation modeling in practice: A review and recommended two-step approach. Psychol. Bull. 1988, 103, 411. [CrossRef]

40. Bagozzi, R.P.; Yi, Y. On the evaluation of structural equation models. J. Acad. Mark. Sci. 1988, 16, 74-94. [CrossRef] 
41. Hsu, C.C. A Study of Participants' Recreational Motivation, Involvement and Flow Experience of Adventure recreational Activity Taking Survival Game as Example. Master's Thesis, Department of Leisure, Recreation, and Tourism Management Southern Taiwan University of Science and Technology, Tailam City, China, 2007.

42. Chu, H.-Y. The Study of Leisure Satisfacation and Well-Bing of Recreational Sports on Elementary School Teachers in Yi-Lan County. Master's Thesis, Department of Physical Education and Kinesiology, National Dong Hwa University, Hualien County, China, 2017.

43. Yang, C.-F. On the Relationships among Social Support, Flow Experience and Well-Being-A Sample from 2009 National Judo Championship Senior High School Players. Master's Thesis, Department of Leisure Services Management, Chaoyang University of Technology, Taichung City, China, 2010.

44. Fornell, C.; Larcker, D.F. Evaluating structural equation models with unobservable variables and measurement error. J. Mark. Res. 1981, 18, 39-50. [CrossRef]

45. Torkzadeh, G.; Koufteros, X.; Pflughoeft, K. Confirmatory analysis of computer self-efficacy. Struct. Equ. Model. 2003, 10, 263-275. [CrossRef]

46. Hair, J.F.; Black, W.C.; Babin, B.J.; Anderson, R.E.; Tatham, R.L. Multivariate Data Analysis; Pearson Education Limited: Upper Saddle River, NJ, USA, 1998; Available online: https:/ / files.pearsoned.de/inf/ext/9781292035116 (accessed on 9 September 2021).

47. Cheung, G.W.; Lau, R.S. Testing mediation and suppression effects of latent variables: Bootstrapping with structural equation models. Organ. Res. Methods 2008, 11, 296-325. [CrossRef]

48. Cheung, M.W. Comparison of methods for constructing confidence intervals of standardized indirect effects. Behav. Res. Methods 2009, 41, 425-438. [CrossRef]

49. Lau, R.S.; Cheung, G.W. Estimating and comparing specific mediation effects in complex latent variable models. Organ. Res. Methods 2012, 15, 3-16. [CrossRef]

50. Chen, C.C.; Yuan, M.Z.; Hsieh, C.H. The effect of leisure motivation and leisure constraint on leisure satisfaction among pickleball players. J. Sport Recreat. Res. 2020, 15, 86-100.

51. James, J. The role of cognitive development and socialization in the initial development of team loyalty. Leis. Sci. 2001, 23, 233-261. [CrossRef] 